\title{
The Use of Media and Technology in Distance Education - Indian Context
}

\author{
Sri Ranganayakula Srinivas (PhD)
}

\begin{abstract}
This paper focuses on the use of media and technology for distance education in India. India being one of the most populous nations of the world has adopted the distance education to cater for its numerous citizens' crave for formal education. This paper, therefore, discusses distance education and the history of media and technology in India with particular reference to the state of Andhra Pradesh. The study found out that despite the growth in the use of media and technology in India, the students in the remote areas were not reached as a result of lack of awareness and adaptability of these modern technology of educating. Useful suggestions were made to educational planners to create awareness on the adaptability of the new technology in distance education in India.
\end{abstract}

\section{Introduction:}

We are living in an age of knowledge and information. The modern societies are being named as information societies, at least in the developed countries. It is rapidly effecting in developing countries like India. Distance Education Technologies (DET) are expanding at an extremely rapid rate. Modern technologies such as computer, communication and media are being utilized in various fields for data processing and quality improvement. Similarly, the same technologies are being utilized in conventional and non-conventional mode of education. The paradigm is slowly shifting from traditional classroom learning to open and distance learning. Since need of 
learners' increased towards new technologies, all pedagogical principles and theories are being changing their form and shape that would emphasize on open and Distance Education. Therefore, instructional designers and curriculum developers have become enamored of the latest technologies in the educational process.

\section{Demography \& Distance Education}

Distance education has emerged as an important form of education in the last few decades. It is the various forms of study at all levels which are not under the continuous immediate supervision of tutors present with their students in lecture rooms or no the same premises, but which nevertheless, benefit from the planning, guidance and tuition of a tutorial organization (Borje Holmberg). In recent years, the offering of open and Distance Education courses and programs have become increasingly popular not only in open universities, but in traditional universities as well (Wheeler, 2002). The terms "Distance Education" or "Distance Learning" have been applied interchangeably by many different researchers to a great variety of programs, providers, audiences, and media. Its hallmarks are the separation of teacher and learner in space and/or time (Perraton, 1988), the volitional control of learning by the student rather than the distant instructor (Jonassen, 1992), and noncontiguous communication between student and teacher, mediated by print or some form of technology (Keegan, 1986; Garrison and Shale, 1987).

The two Phenomena are exploding in the world, those are Demography and Knowledge. The number of college going youth is multiplying fast on account of the reputation attached to the University degrees, while the number of colleges which may absorb this out flow has not kept pace with the population explosion. It may also be added that the present socio- 
economic milieu has made the modern youth increasingly gripped by the psychology of "learn while you earn" (Inayat Khan 1991). To cater the demands of increasing population there was a necessity to extend educational facilities in distance and open mode. The wild craze for degrees and diplomas has made "Distance Education" and particularly the posted countries "to acquire roots in third world countries in quite distinct way thus the related scenario in developed realm" (Prof. S.S. Chib). The social strata of the population is varied and scattered in different geographical contours. It was very difficult to this varied population to continue formal education after their schooling. The population of India is 1,02,8610,328 according to 2001 census; this is expected to increase from 1029 million to 1400 million during the period 2001-2026 - an increase of 36 percent in twenty- five years at the rate of 1.2 percent annually. - Out of the total population increase of 371 million between 2001 and 2026, the share of the workers in the agegroup 15-59 years in this total increase is 83 percent. This has implication in the productivity of labour in future. The urban population in the country, which is 28 percent in 2001 , is expected to increase to 33 percent by 2026 . The urban growth would account for nearly half (49 percent) of total population increase by 2026 . Out of the total population increase of 371 million during 2001-2026 in the country, the share of increase in urban population is expected to be 182 million. The demographic projections suggest that by 2026, the population of India will reach 1,384 million. Therefore the demand has been increasing in India to cater educational opportunities to this growing population.

The democratization of the masses is possible only by providing education for all at all levels. To achieve this objective the central and state governments have established open universities and distance mode of education in traditional universities. These universities are framing the curriculum in the interests of different castes and classes that would bring 
national integration. Today, political and public interest in Distance Education is especially high in areas where the student population is widely distributed. Each region has developed its own form of Distance Education in accordance with local resources, target audience, and philosophy of the organizations which provide the instruction. Many institutions, both public and private, offer university courses for selfmotivated individuals through independent study programs. Students work on their own, with supplied course materials, print-based media and postal communication, some form of teleconferencing and/or electronic networking, and learner support from tutors and mentors via telephone or E-mail.

The instructional media evolved, from print, to radio, television, telephone, computer to current interactive technologies. In the beginning most of the universities conducted courses under distance mode through correspondence courses in Europe and spread to all over the world. This was the accepted norm until the middle of this century, when instructional radio and television became popular. According to Margaret Cambre (1991), in the late 1950's and early 1960's, television production technology was largely confined to studios and live broadcasts, in which master teachers conducted widelybroadcast classes. In the 1970 's, as professionally designed and produced television series introduced students to new subject matter that was not being currently taught, yet was considered to be an important complement to the classroom curriculum. Then, in the 1980 's, the pendulum swung back to the basics. The most recent trend has been one of multiculturalism, humanities, and world affairs. The major drawback of radio and broadcast television for instruction was the lack of a 2-way communications channel between teacher and learner. In recent times these technologies are replaced by computer 
based communication such as e-mail, Internet, World Wide Web, Audio and Video conferences.

\section{Distance Education in Andhra Pradesh (AP):}

Andhra Pradesh is the fifth largest state in India accounting $8.4 \%$ of India's territory. It is divided into 23 districts and three natural regions; 10 Telangana districts, 9 Coastal districts called Andhra and 4 Rayalaseema districts. According to 2001 census it comprises 7.5 million populations and growth rate of population is $13.86 \%$. It is also fifth largest state in population in India. There are 28,123 villages and 1,100 Mandals (zones) and $72.92 \%$ of population lives in villages in A.P. The literacy rate of this state is $65.38 \%$ in 2001 which is lower compare to All India average. There are 14 state universities, 2 central universities and 7 deemed universities in this state.

Andhra Pradesh is one of the few Indian states which recognized very early the potential and role of Distance Education in the process of democratization of education. It is a birth place of India's first Open University (P. Satyanarayana 2002). The first distance higher education programme in the University sector began in Andhra University (AU) in 1972. In spite of the psychological and emotional resistance from the conventional academics, distance education began to spread slowly, and then Sri Venkateshwara University (SVU), and Osmania University (OU) began distance education programs. In new and prestigious era in the history o Distance Education in Andhra Pradesh began with establishment of APOU (now called Dr. B.R.Ambedkar Open University) in 1982. The newly set up distance teaching University pioneered the modern communication technology based distance higher education in the state. This is an instrument to equalize the higher educational opportunities in the state. The first State Open

University paved the way for the founding of eight other State 
level Open Universities and one National Open University i.e., Indira Gandhi National Open University.

The history of Distance Education in AP has five generations. $1^{\text {st }}$ generation consists of External study mode of education, $2^{\text {nd }}$ generation consists of Correspondence Education with good print materials sent by post to the students, $3^{\text {rd }}$ generation consists of Correspondence Education with good selfinstructional print materials, assignments and contact programmes, the $4^{\text {th }}$ generation consists of Correspondence Education with 2-way communication and audio-video support and $5^{\text {th }}$ generation consists of SIM, 2-way communication, contact classes, Broadcasts, Telecasts, Teleconference and Computer Interactivity. The Open University system reflects the $5^{\text {th }}$ generation Distance Education. Most of the traditional Universities are providing open and Distance Education (Duel Mode) and BRAPOU (Dr. Bhimrao Ambedkar Open University) and IGNOU (Indira Gandhi National Open University) are offering various courses under open education mode. Presently, study centers of more than 50 universities are operating from AP. It indicates there is great demand from students for open and Distance Education. For instance, enrollment of students in Dr.BR Ambedkar Open University at under graduate level as follows

Shows Number of Enrolled Students and Number of Students that took Examination of BRAOU:

\begin{tabular}{|l|l|l|l|l|l|l|}
\hline & \multicolumn{3}{|l|}{ Enrollment } & \multicolumn{3}{l|}{ Took Examination } \\
\hline $\begin{array}{l}\text { Year of } \\
\text { Admission }\end{array}$ & Male & Female & Total & Male & Female & Total \\
\hline $1999-2000$ & 43540 & 15400 & 58940 & 25813 & 10699 & 36512 \\
\hline $2000-2001$ & 51295 & 19837 & 71132 & 20752 & 10394 & 31146 \\
\hline $2001-20012$ & 35668 & 18052 & 53720 & 20066 & 11243 & 31309 \\
\hline
\end{tabular}

Table 1: Source: BRAOU, 2006. 


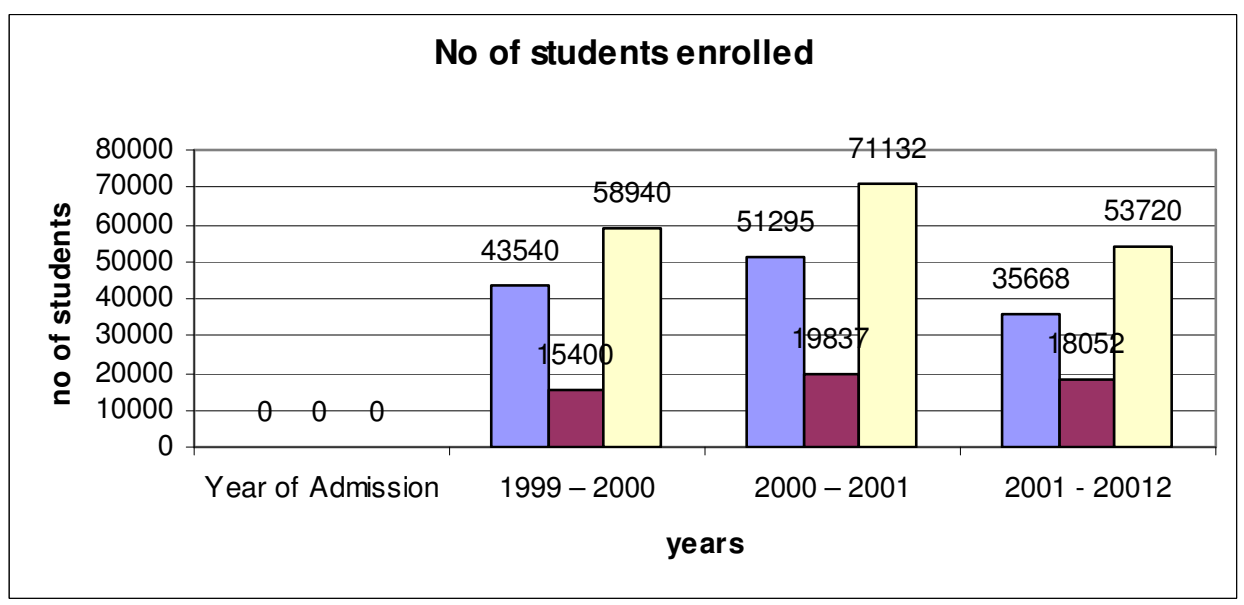

Source: BRAOU, 2006.

The above Bar Graph indicates that there are more enrolments during 2000-2001, but the number students enrolled during 2001-2002 is decreased in DR.B.R.Ambedker Open University because of many single mode and traditional Universities in Andhra Pradesh have been switched to duel mode of education i.e., regular admissions and Distance mode of admissions in 2001-202. This is why students took admission into such universities which are near to their vicinity at under graduate level.

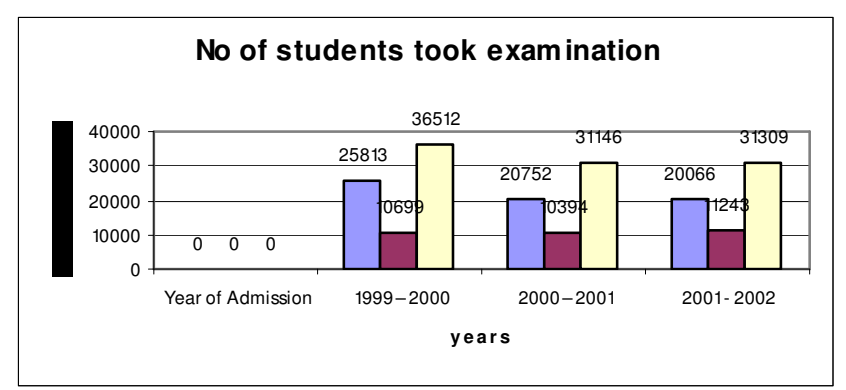

\section{Source: BRAOU, 2006}

The above Bar Graph indicates that there the number of students at under graduate level who have taken examination in DR.B.R.Ambedker Open University. These numbers are 
considerably less than the enrolment due to drop outs. Though the number students who took examinations are considerably good and indicating the importance of Distance Education. This number is as equal as to any single mode university.

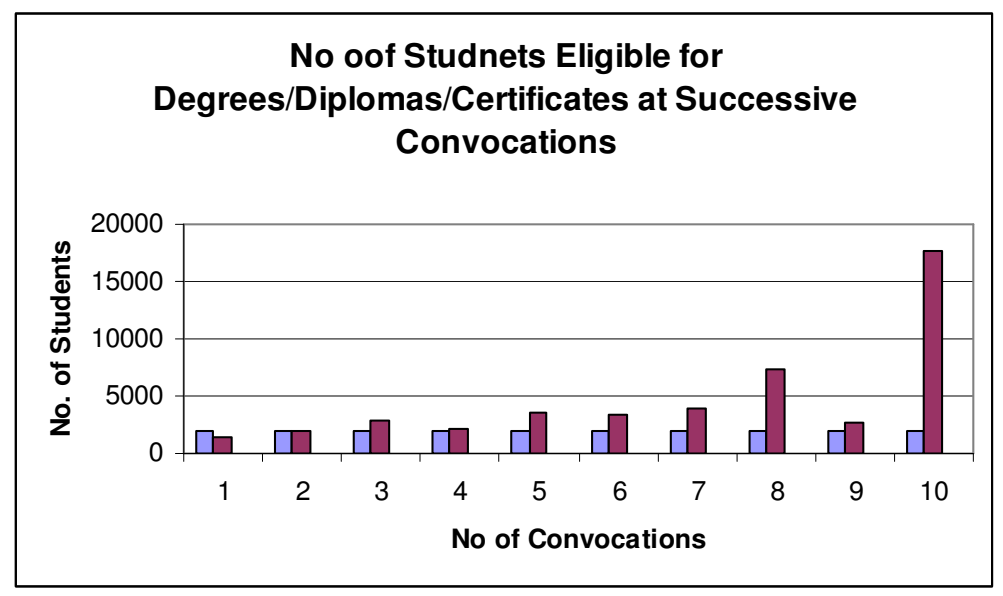

Source: BRAOU, 2006.

The above Bar graph is revealing that the number students who have graduated in different courses such as certificate courses, undergraduate courses and post graduate courses. Above figures indicate that most of the enrolled students who were dropped out also have appeared the examinations and completed their courses, therefore in 2001 there many students were graduated in their respective courses. These study centers are equipping with technology in order to impart quality education and to attract the students by providing new media and technologies. This is again indicating the importance of Distance Education. 


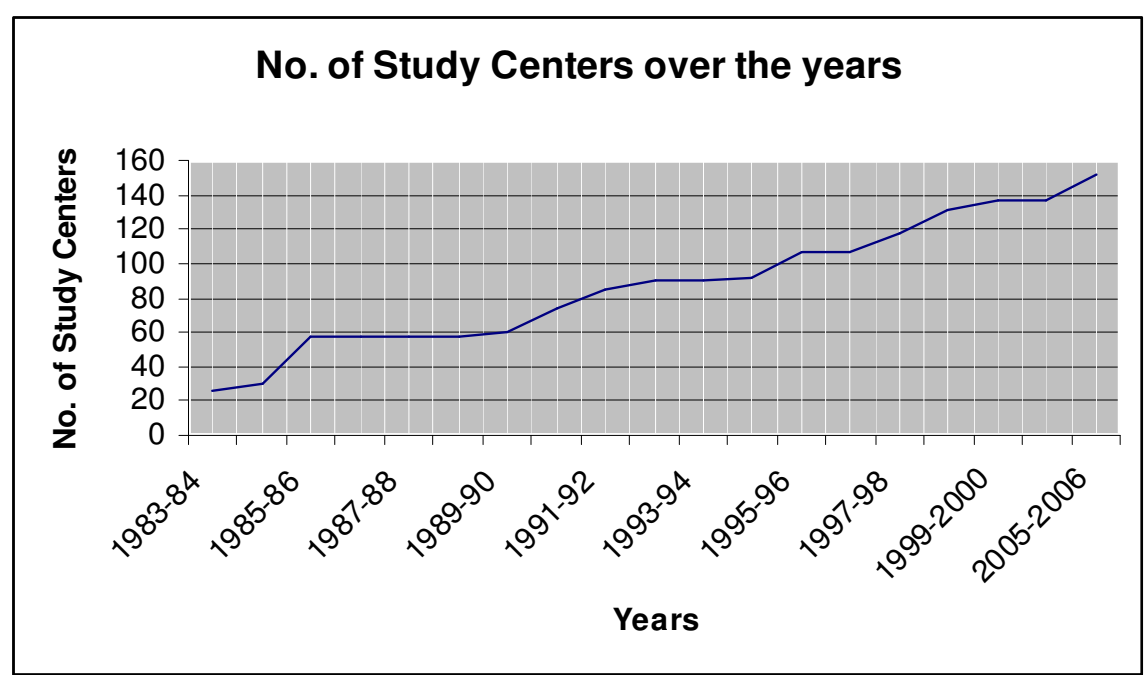

Source: BRAOU, 2006.

The above graph shows that the rapid increasing of number of study centers of Br.BR Ambedkar Open University all over the state of Andhra Pradesh. In the beginning there were only 25 study centers by 2006 the number rose to 152 . Since the importance has been increased and the degrees awarded to the students are as valid as the degree of single mode traditional universities, the working people realized to up date their qualifications for various purposes. This trend has been forced the single mode traditional universities to open some form of distance and continuing education. Including technological universities like Jawaharlal Nehru Technological University (JNTU), Hyderabad (capital of AP) also started directorate of Distance and Continuing education and enrolling the working technical people as their students to up grade or enhance their qualifications for promotion purposes.

Traditionally, we think of distance learners as adults. Whole institutions of higher learning, such as the BRAOU, IGNOU, PGRR (Prof. G. Rami Reddy Center for Distance Education of 
Osmaina University) and SDLCE (School of Distance Learning and Continuing Education of Kakatiya University), JNTU etc., have been successfully dedicated to providing Distance Education at the post-secondary level for decades. The adult learner tradition is now changing as new programs, such as Communicative Skills, Mushroom Cultivation, Nutrition Concepts, Lab-Technician courses, Fashion Technology, Management courses, Engineering, Bio-Technology, Agricultural Sciences, Pharma-Sciences, Library and Information Sciences and computer sciences. These courses emphasis in practicum not only theory, therefore the study centers where the students of these courses enrolled should equip with modern Media and Technology otherwise the objectives of Distance Education will not be achieved.

\section{Media and Technology}

Media and Technology can be distinguished. The term media describes a generic form of communication association with particular ways representing knowledge. Each medium not only has its own unique way presenting knowledge, but also organizing it (Dr. P. Satyanarayana, 2002). With regard to cognitive learning goals, individual guidance over modern media and technology would appear to be valuable as a medium for fulfilling the certain teaching functions, they are:

- Activating Motivation

- Directing attention

- Stimulating recall of relevant prerequisites

- Providing learning guidance

- Providing feed back (Baath, 1979).

The interactive and non-interactive media and technologies are being used in Distance Education for above said purposes are: 


\begin{tabular}{|c|c|c|c|}
\hline Media & Technology & Non-interactive & Interactive \\
\hline Text & $\begin{array}{l}\text { Printing Machines, } \\
\text { Computers }\end{array}$ & & \\
\hline Audio & $\begin{array}{l}\text { Cassettes, Radio, } \\
\text { Broadcasting TV, }\end{array}$ & $\begin{array}{l}\text {-Radio } \\
\text {-Audio Tapes }\end{array}$ & $\begin{array}{l}\text {-Telephone } \\
\text {-Audio } \\
\text { teleconferencing }\end{array}$ \\
\hline Video & $\begin{array}{l}\text { Telecasting, Video } \\
\text { cassettes, Discs, Cable, } \\
\text { Satellite, Fiber Optics, } \\
\text { ITFS, Microwave, Video } \\
\text { Conferencing. }\end{array}$ & $\begin{array}{l}\text {-Open telecast television } \\
\text {-Cable television (1 way) } \\
\text {-Video tapes } \\
\text {-Instructional television fixed } \\
\text { services (ITFS) } \\
\text {-Satellite television (1 way) } \\
\text {-Show scan / freeze frame } \\
\text { television (1 way) }\end{array}$ & $\begin{array}{l}\text {-Microwave } \\
\text { - Cable television (2 } \\
\text { way) } \\
\text {-Satellite television (2 } \\
\text { way) } \\
\text {-Show scan / freeze } \\
\text { frame television (2 } \\
\text { way) } \\
\text {-electronic black board } \\
\text {-Video } \\
\text { teleconferencing }\end{array}$ \\
\hline Computer & $\begin{array}{l}\text { Computers, } \\
\text { Telephones, Satellite, } \\
\text { Fiber Optics, ISDN, CD- } \\
\text { ROM, CD, DVD, } \\
\text { Modem etc., }\end{array}$ & & $\begin{array}{l}\text {-computer assisted } \\
\text { instruction } \\
\text {-computer based } \\
\text { instructional } \\
\text { management }\end{array}$ \\
\hline
\end{tabular}

A distinguishing feature of distance education system is its multi-media instructional system which combines different forms of media depending on need. It is learner based. In this system teachers are absent and learners are independent and mostly learn for themselves with the help of multi-media instructional packages.

Although technology is an integral part of Distance Education, any successful program must focus on the instructional needs of the students, rather than on the technology itself. It is essential to consider their ages, cultural and socioeconomic backgrounds, interests and experiences, educational levels, and familiarity with Distance Education methods and delivery systems (Schamber, 1988). Students usually adapt more quickly than their teachers to new technology. On the other hand, teachers who have begun to feel comfortable with the equipment don't mind having their students teach those new tips and tricks (Apple Classrooms of Tomorrow, 1992). The 
most important factor for successful distance learning is a caring, concerned teacher who is confident, experienced, at ease with the equipment, uses the media creatively, and maintains a high level of interactivity with the students.

While using modern media and technology, care must be taken to ascertain the percentage of learners, who have access to these media gadgets. Also, look at the availability of community listening/viewing/browsing centers. Regarding use of media and technology the University should consider the following aspects;

- Identification of target population

- Psychological characteristics and socio-economic needs of students

- Academic needs of target students.

- Technique of course presentation.

- Materials to be utilized in the series.

- Selection of script writers, broadcasters and media experts.

Implementation of any new media and technology in Distance Education depends up on the awareness, availability, adoptability, acceptability, accessibility and affordability level of students. These are again depending up on the socio-economic conditions, cultural aspects, and geographical factors. Especially, Indian society divided caste wise and class wise, for long generations the upper cast people are enjoying and lower caste people are denied to access or use the resources. The Open Universities in distance learning mode are providing such opportunities and slowly democratization of education is prevailing in rural area. The impediment factors of distant learner to be marginalized in order to use these modern gadgets fruitfully. 


\section{Awareness of Technology}

Far most important aspect of Distance Education is awareness of Media and Technology. First, all teachers who discharge the duties as counselors at study centers should aware the different types Media and Technology and how to use them in distance mode of education. The University should equip required set of Media and Technology at their study centers. Some open universities like Dr. BR Ambedkar Open University (BROU) and Indira Gandhi National Open University (IGNOU) are providing certain Media and Technology such as radio, TV, audio tapes, video tapes, Tele-Conferencing, CD-ROMs, Computer with limited Internet facilities to their study centers through which students avail them during contact classes and use their leisure time. But these facilities are not providing opportunities to use them by all the students who enrolled at particular study centres. One of the main problems is the counselors are not well aware of the use of Media and Technology because of their traditional mind set up and rural background. If they are trained in using Media and Technology, at least they can use them at study centers during contact classes. Then students get awareness and learn how to use them. Therefore "Media and Technology" should be introduced as one of the subjects for all courses in Distance Education. If this subject becomes compulsory then students will acquire the knowledge of various forms of media and use of them and few practical classes to be conducted with the help of self instructed material (SIM). The attitudes of the learners would change and they will attract to these new technologies. This reinforces them to self study in achieving their aims and objectives. Hence, awareness of Media and Technology is one of the most important factors that play vital role in assuring the quality of Education, and it is must in Distance Education because there if formal class and face to face teaching and learning. Another problem is associated with this aspect is, the socio-economic background of students. 
Many of them belong to remote rural areas and backward class, so they are not exposed to these new technologies. If the special care taken and more interactive sessions are conducted at study centres in new environment would help them to get aware of new media and technology. In my case study also it is evident that and indicated in below table-1, at Under-Graduate level 166 distance students out of 300 have awareness of Radio educational and TV educational programmes, but only 40 students have got knowledge of Internet. The students who are aware of these media and technologies have background of urban and better economic conditions. Though there is availability of certain media and technology at study centres are not used fully by the students because of their geographical, socio and economical conditions.

\section{Use of Media \& Technology at Under-Graduate Level}

\begin{tabular}{|l|l|l|l|l|l|l|l|l|l|l|l|l|}
\hline $\begin{array}{l}\text { Edn. } \\
\text { Level }\end{array}$ & \multicolumn{3}{|l|}{ Radio \& TV } & \multicolumn{3}{l|}{ Telephone } & \multicolumn{3}{l|}{$\begin{array}{l}\text { Audio/Video } \\
\text { Tapes }\end{array}$} & \multicolumn{3}{l|}{ Internet } \\
\hline & Y & N & T & Y & N & T & Y & N & T & Y & N & T \\
\hline BA & 65 & 35 & 100 & 08 & 92 & 100 & 40 & 60 & 100 & 03 & 97 & 100 \\
\hline B.Com & 56 & 44 & 100 & 11 & 89 & 100 & 33 & 67 & 100 & 11 & 89 & 100 \\
\hline B. Sc & 45 & 55 & 100 & 18 & 89 & 100 & 34 & 66 & 100 & 26 & 74 & 100 \\
\hline
\end{tabular}

Table: 2; Source: Survey 2006

\section{Adoption of Technology:}

Awareness of technology leads to the adoption of them. Once awareness society is created then slowly the student community will try to adopt the technology. Adoption is need based. Purchasing and maintaining appropriate equipment, and training teachers and facilitators to use it effectively, are necessary conditions. There are other factors involved, many of which are affective rather than cognitive, such as userfriendliness and the ability to implement learner support. But many universities are traditionally hierarchical and bureaucratic, 
whereas new technologies challenge this model. Talab and Newhouse (1993) have found that many teachers are slow to incorporate new technologies into their classrooms. On the other hand, the technological innovations that have been adopted by teachers are those which solved problems that the teachers themselves identified as important. Successful technological innovations must take into consideration the social and political climate of the university, and must also reinforce the authority of the teacher, rather than undermine it. The creative teachers are using computers and other learning technologies to enhance and enrich their teaching. But first, four interrelated conditions must be met:

- training in the skills needed to work with technology

- education providing vision and understanding of stateof-the-art developments and applications

- support for experimentation and innovation

- Sufficient time for learning and practice (US. Congress, 1988, p. 16).

The approach of educators and authorities in Indian universities is conservative and they do not accept these new technologies very easily. The mind set of this elite class should be changed. Still most of universities are not fully utilizing these available world technologies. Because of this reason the Indian students are logging behind compare to developed nations. So adoption is one of the most important phenomena in accepting and implementing new technologies in Indian universities. However, some educators, who are working with new vision, of some universities such as Indira Gandhi National Open University (IGNOU), BR Ambedkar Open University (BRAOU) and other universities are trying to bring these new technologies into distance mode of education in order to improve the quality and standards of the students. 


\section{Accessibility of Technology:}

The technology chosen must be available to the learners otherwise it may not be use however pedagogically and theoretically should it may be. The Universities that are providing Distance Education should equip and facilitate needed media and technological tools such as Radio, Audio Tapes, and Video Tapes, Computers with Internet facility and online Video or Tele Conferences in their study centre, so those students who enroll in such study centers will avail these technologies. These supplement their print material and compensate the face to face instructors. BRAOU and IGNOU are providing certain media and technology components in their study centers; they reached the land mark of using Tele and Video conferencing via satellite through Training and Development Communication Channel (TDCC). The learner should to nearest reception center to avail this facility. On that particular day students can interact with the experts and get clarifications. But many a times it is difficult to find the students on these particular days, even the students turn on these days and who avail this facility, they use this opportunity to clarify their doubts on non- academic issues like knowing about fee structure, date of examination etc., etc., But most of the Universities which are running dual mode of education are not providing these facilities which need of use of modern media and technology. At the most they are using only print media. This does not encourage the students to be active and effective. Around $40-50 \%$ of students are accessing these technologies at study centres mainly listening to audio cassettes and video tapes. BRAOU is broadcasting on All India Radio (AIR) its programmes on four days a week six $30 \mathrm{~min}$ slots on Hyderabad "B" station.

Collaboration between MHRD, Doora Darshan (DD- Indian Govt. TV), IGNOU has resulted in DD Gyan Darshan, the educational channel of India in 2000 . The channel is providing 
educational programmes on a variety of subjects for 19 hours a day to enhance through different cable operators in the country for wider out reach. IGNOU also offering one FM channel in 40 cities and towns for educational development. Interactive Radio live couselling is provided by inviting experts. Students can ask questions right from their homes on telephone. These sessions are conducted for an hour on Sundays from 189 radio stations of the country. Students can listen the live radio sessions but the question is having telephone facility at their home. Again this opportunity is used by elite and upper middle class section. Reaching to unreachable sections remains a question till the socio-economic conditions are improved. However, Distance Education is open an opportunity to these section of students at its level best.

\section{Acceptability of Technology:}

The teachers and the learners concerned should have a favourable attitude and proper orientation to use the media available. Without such a positive orientation of the both, the success of whole exercise in the multi-media may turn out to be a face. There is always resistance in accepting new technologies when they are introduced. Especially the Indian philosophy of people does not accept easily the modern and new concepts in any area or field. This reflects in Distance Education also. The teachers who habituated to teach in traditional way feel the out dated or conventional methods of delivering instruction are perfect and good. This is inherited in the blood and soul and the same way learners are trained to acquire knowledge in traditional classroom with conventional practices. This is the era of information technology, if the Universities do not accept and implement these technologies, they never forward further. Therefore firstly the Universities should give series of orientation classes to its stakeholders to move along with world technology. Though print media is base 
but it can be supplemented by the new media and technologies in imparting effective teaching and learning. These efforts are being made in BRAOU, IGNOU and few other Open Universities.

\section{Economics of Technology:}

It is evident that technologies will not be selected if they are very expensive. In fact, economies of scale, i.e. money involved in the use of technology is the ultimate consideration in choosing the media. In fact, most of the Universities which are providing education through distance or open mode are collecting relatively high fee from the distance students compare to regular mode students. Students also do not feel of this high fee because most of them are self employed, serving in private and government sectors. They earn money so it is not much difficult to them to afford. But the amount that is collected by the Universities is spending for its distance students to provide new technologies. Most of the Universities are washing their hands just after supplying print materials and some of the Universities even not providing these print materials. It indicates that such Universities are running Open and Distance Education as their revenue sources. In addition to this, University Grants Commission (UGC) is also not intervening at right time. Since the Universities are collecting lot of revenue from distance students, they can facilitate minimum technological equipment at their study centers with $50 \%$ of fee paid by students. Therefore UGC should monitor and instruct to its stakeholder universities to set up require laboratories and other media and technologies in order to strengthen Distance Education. In case of BRAOU and IGNOU are setting up new study centers every year and equipping with these new technologies to reach the unreachable sections and remote areas. But there are more than 50 duel mode Universities operating in AP, admitting the students in their distance mode are very poor in facilitating these new 
technologies to their students of distance mode. This is very true in most of the duel mode Universities because still administrators and academicians feel that the conventional mode of education is superior to distance mode of education. In fact, these Universities are running distance education along with their conventional mode just because of income generation.

\section{Validity of Technology:}

Last but not least, the technology selected must be appropriate for the institutional objectives and the contents of the courses of the taught in the institution. Say, if a course can be taught more effectively through a video tape than print, it is better to select video as the medium. If another course can be taught equally well through two or more media, it is wiser to choose the least expensive medium. To evaluate the validity of technology that is being implemented at institution there is a need of setting up Media and Technology center at university level. This should work along with content experts. This center can advise regularly to its stakeholder institutions in acquiring and selecting the Media and Technology. Annual inspections can be done and based on the evaluation report the curriculum experts can advise these institutions to carry out which type of courses they can run in subsequent years. This will enhance the teaching learning process and validity is maintained.

In view of aforesaid factors, the media chosen varies from country to country and institution to institution. For example, the British Open University (UKOU) follows the integrated approach to media use. The UKOU gives $90 \%$ of the course materials in print and the remaining $10 \%$ of the material is given through electronic media. The Central Radio and Television University (CRTVU) in the Peoples' Republic of China follows the multi-media approach in which the radio and the 
television are the master - media supplemented by printed teaching materials. The reason is that such an approach suits the university's requirements to train large numbers of technical and management personnel and qualified teachers in the country. On the other side, the Fern University of Germany uses the print as its master-medium, in spite of the fact that Germany is one the most advanced countries in communication technology. The logic lies is that the academic tradition in Germany affirms the inherent superiority of print medium over the non-print media. The University of Air in Japan uses the radio as its master media. The University of Distance Teaching, in Costa Rica uses a variety media such as the textbooks, television programmes, audio cassettes, telephone teaching, regular face-to-face session at weekends etc., to provide higher education to a larger number of people and also train people for agriculture and industry.

In India, The Indira Gandhi National Open University (IGNOU) follows multi-media approach in its distance teaching system. The print materials are the master-media which is supplemented by audio and video programmes and face-to-face counseling sessions. Recently, the IGNOU has also used teleconferencing in its distance teaching on an experimental basis. IGNOU also opened its study centers abroad, there are such two centers opened in Ethiopia, they are located one at Addis Ababa University and other in Haramaya University. IGNOU is also collaborating with other Universities abroad.

In completion, going through the preceding description, it is clear that no one media is complete and perfect for all types teaching. It is evident that among various media, one is supported by other. Therefore, the use of mix of media i.e., multi-media, the more through and effective will be the instructional process in Distance Education. However, we reached at remarkable stage or level in Distance Education. But 
there are many areas to be strengthened in order to impart the Education to the unreachable sections of population. Some of them are can be sorted out immediately with out inputting any money and some of them may take time and need money. For further improvement in use of Multi-Media in Distance Education the following suggestions can be exercised.

\section{Suggestions:}

- Media and Technology to be introduced as a subject to all Open Distance Learning (ODL) students to develop awareness to the Learners and Teachers.

- Available Media and Technology to be explored and utilized at maximum extent in order to enhance the quality of Distance Education.

- Mandatory training to be provided to all the counsellors in using proper technology that to be used in their classes at contact classes.

- Sufficient funds to be allocated to distance mode of education to procure the modern technology.

- Teachers should change their traditional way of thinking and to adopt modern ways of thinking in using media and technologies.

- Digital lessons and Library should be prepared and kept in web sites of universities for the use their students..

- Regular interactions between Teacher and Learner to be maintained through e-mails.

- Flexible Learning sessions to be arranged according to targeted students time schedules.

- All forms of traditional implementations to be diminished at all levels in Distance Education. 
- Online exams to be arranged to the students of Distance Education and scope to be given to then to write exams according to their leisure.

- Educational TV channels should be started or improved and programmes should be telecast for 24 hours in a day, so this gives a learner more flexibility to learn.

- There should not be any traditional implementation in planning, execution and feed back in Distance Education.

- The libraries should be digitized and all the books should be available on Web to their stakeholders.

\section{Conclusion:}

Distance Education is fast growing mode of education in India. It gives more opportunities to rural and urban working population. This enhances the standards of life of these sections. Initially the awareness of Media and Technology should be given and motivate all the stake holders of Distance Education to adopt it. The traditional thinking should to be diminished and modern thinking to be cultivated in the minds of Teacher and Learner of Distance Education. The environment should be created to reach the fruits of Distance Education to all parts of country mainly unreachable sections of population. More flexibility encourages students to continue their education and minimize the drop out problem so all traditional practices should be marginalized in Distance Education. Work and Education will yield the greater crops and make our country to stand in first row where developed countries are standing. 


\section{References}

AAUP (1998). Distance Learning. Academe, 84 (3), 30-38.

American Journal of Distance Education Vol. III, 2002.

Bates, A.W. London: (1995) - Technology, Open Learning and Distance Education: Routledge London.

Baath. JA (1979): Correspondence Education in the Light of a number of Contemporary Teaching Models, Liber Hermodes, Mulmo.

Cambre, M.A. (1991). The state of the art of instructional television. In G.J. Anglin, (ed.), Instructional technology, past, present, and future (pp. 267-275). Englewood, CO: Libraries Unlimited.

Collins B (1996): Tele Learning in Digital World: The Future of Distance Education, International Thomson Computer Press, London.

Daniel JS (1996): Mega Universities and Knowledge Media: Technology Strategies for Higher Education, Kogan Page London.

Distance Education (2001): Conference Papers vol. I \& II.

Gajaraj Dhanarajan - Open and Flexible Learning:

Commonwealth Experience and India's Challenge.

Holmberg,B (1990): Perspectives of Research on

Distance Education, Fern Universiatat, Ziff, Hagen.

Keegan, D. (1986). The foundations of distance education.

London: Croom Helm

Khan, Inayat (Ed-1991) -Distance Education Some

Readings: New Delhi: Amar Prakashan Publishers.

Lock wood, F (1995): materials Production in Open and Distance Learning, Paul Chapman, London.

Manjulik S \& Reddy VV (1996): Distance Education in IndiaA Model for developing Countries, Vikas, New Delhi.

Mason R. (1994): Using Communications Media in Open and Flexible Learning, Kogan Page London 
Mulay V (1986): Correspondence Educationin Indian Universities - A Review, UGC, New Delhi.

Murali Manohar K (Ed 1996) Distance Education - Theory and Practice: Media and Communication Technology Vol II - Open Learning Society, Hyderabad.

Panda, S (Ed-1999): Open and Distance Education, Aravali Book, New Delhi.

Perraton, H. (1988). A theory for distance education. In D. Sewart, D. Keegan, \& B. Holmberg (Ed.), Distance education: International perspectives (pp. 34-45). New York: Routledge.

Perraton H (1982): Alternative routes to formal education: distance teaching for school equivalency, John Hopkins University Press, Baltimore.

Pillai CR, Naidu CG (1997) - Economics of Distance Education - The IGNOU Experiences: Planning and Development Division, IGNOU.

Satyanarayana P (2000) - Distance Education What? Why? How? - Book links Corporation, Hyderabad.

Satyanarayana P (2002) - Distance Education in AP Policies: Practices: Perspectives - Bookinks Corporation, Hyderabad.

Schamber, L. (1988). Delivery systems for distance education. (ERIC Document Reproduction Service No. ED 304 111).

Schramm (1997) - Big Media, Little Media, Tools and Technology for Instruction, Sage, Beverly Hills.

SDLC Decennial Celebrations (2001) - Conference Papers, Published by SDLC, KU, Warangal.

Talab, R.S., \& Newhouse, B. (1993, January). Self-efficacy, performance variables and distance learning facilitator technology adoption: Support for the teacher needs hierarchy. In Proceedings of Selected Research and Development Presentations at the 
convention of the AECT, Research and Theory Division, New Orleans.

Venkaih V, Satyanarayana P (2006) Quality Assurance Series Manual for Management of Study Centers: BRAOU, Hyderabad.

Vijaya Laxmi P (Ed 2006): Spectrum - research contributions of India's First Open University - Silver Jubilee - Volume - BRAOU, Hyderabad.

VijayaLaxmi Pandit (2004): Student Support Services in ODL a case study of BRAOU - Book links Corporation, Hyderabad.

Census of India, 2001: Indian Government 2001 census abstact. 